\title{
Socio-demographic factors and suicidal behavior among the patients with psychiatric disorder attending outpatient department of a tertiary level hospital
}

\author{
Shahana Parveen, ${ }^{1}$ Avro Das Bhowmik, ${ }^{2}$ Mekhala Sarkar, ${ }^{3}$ Mohammad Tariqul Alam, ${ }^{4}$ Mohammad Akteruzzaman, ${ }^{5}$ \\ Panchanan Acharjee ${ }^{6}$ \\ ${ }^{1}$ Assistant Professor (Psychiatry), National Institute of Mental Health (NIMH), Dhaka, Bangladesh; ${ }^{2}$ Associate Professor (Psychiatry), \\ NIMH, Dhaka, Bangladesh; ${ }^{3}$ Associate Professor (Psychiatry), NIMH, Dhaka, Bangladesh; ${ }^{4}$ Associate Professor (Psychiatry), \\ NIMH, Dhaka, Bangladesh; ${ }^{5}$ Assistant Professor, Pediatrics, Mugdha Medical College, Dhaka, Bangladesh, ${ }^{6}$ Assistant Professor \\ \& Head, Department of Psychiatry, Chittagong Medical College, Chattogram, Bangladesh.
}

Article info:

Article info

Received : 01 Jan, 2020

Accepted : :02 May, 2020

Number of tables : 02

Number of figures : 00

Number of refs : 25

\section{Correspondence}

Shahana Parveen

Mobile: +8801819117321

E-mail: shahanabmc1@gmail.com

\section{Summary}

The majority of suicides worldwide are related to psychiatric disorders. Overall, suicide rates vary concerning the age, gender, and socioeconomic status of the individual and the method of suicide. The objectives of the study were to find the socio-demographic factors and suicidal behavior associated with suicidal attempts in patients with psychiatric disorders. A cross-sectional, hospital-based, descriptive study was conducted among the patients attending the psychiatry outpatient departments (OPD) of the National Institute of Mental Health, Dhaka, Bangladesh. A total of 98 consecutive cases were included those who were at and above18year, have a definite psychiatric disorder and history of suicidal attempt. The data were collected by face-to face interview using semi structured questionnaire. The study identified that most of the patients were in the age group 21-30 years $(53.1 \%)$, mean age \pm SD was $27.02 \pm 8.42$, more in female $(66.2 \%)$, housewives $(35.7 \%), 57.1 \%$ were from an urban background and $35.7 \%$ of them studied up to SSC. The vast majority $(73.5 \%)$ came from a nuclear family. Suicidal behavior revealed that mean suicidal attempt was $2.63 \pm 2.84$, Communication intent was $20.4 \%$, Suicidal note was put by $10.2 \%$, at home (90.8\%),59.2\%, sample choose day time and common method were hanging $(25.5 \%)$ and medicine $(22.4 \%)$. Help nearby in $72.4 \%$, precaution against rescue was $18.4 \%$, intent to die was $65.3 \%$ and hospitalization needed for $34.7 \%$ cases. Suicides can be prevented by early identification, diagnosis and proper intervention of psychiatric disorder among risk groups. Restricting access to means of suicide, by training caregivers, provide adequate follow-up care may reduce impulsive suicidal attempts.

Bang J Psychiatry 2018;32(1): 14-18

\section{Introduction}

Suicide is defined as self- inflected death. A suicide attempt is defined as a potentially self- injurious act committed with at least some wish to die, whether or not any injury occurs. Suicide is a major health problem with a mortality rate of $1.4 \%$ of all deaths worldwide. Most suicides are related to psychiatric disease, while depression, substance use disorders and psychosis is the most relevant risk factors ${ }^{1}$ Suicidal behavior includes a wide range of self-destructive behavior or self-damaging acts in which people engage. Suicidal behavior is further divided into fatal and non-fatal suicidal behavior. Fatal suicidal behavior refers to completed suicidal behavior with the victim's intent to die.
According to Schlebusch, non-fatal suicidal behavior includes attempted suicide (survival of intended suicide) and para-suicide (no intention to die). ${ }^{2}$

Although the etiology of suicide is not well-understood, the presence of psychiatric disorders is one of the strongest risk factors for suicide attempts and suicide deaths. ${ }^{3}$ Indeed, psychological autopsy studies suggest that more than $90 \%$ of people who die by suicide have a diagnosable mental disorder. ${ }^{4}$ Family and genetic studies similarly have suggested that the cooccurrence of suicide ideation within family members is explained by the presence of mental disorders, but that the tendency to act on suicidal thoughts is not, and instead may result in a distinct 
genetic component perhaps related to the presence of impulsiveaggressive traits. ${ }^{5}$ Virtually all mental disorders carry an increased risk of suicidal ideation; suicidal attempt and suicide. ${ }^{6}$ Psychiatric patients risk for suicide is 3 to 12 times of non-patients. The degree of risk varies depending on age, sex, diagnosis and inpatient or outpatient status. For male and female outpatients who had never been admitted to a hospital for psychiatric treatment, the suicide risk is three to four times greater than the general population. ${ }^{7}$ Physical methods were more frequently used by those with unequivocal intent to die, those from extended families, repeaters, substance abusers, and psychiatric patients other than depressives. ${ }^{8}$ In the above context, it was intended to study the socio-demographic risk factors and behavior associated with suicide attempts in patients with psychiatric disorders attending OPD of a tertiary level hospital. The specific objectives of this study were to evaluate socio-demographic risk factors, as well as to see the pattern of suicidal attempts.

\section{Materials and methods}

The current study is a cross-sectional, hospital-based, descriptive study conducted among the patients attending the Psychiatry Out-Patient Departments (OPD) of the National Institute of Mental Health (NIMH), Dhaka, Bangladesh. The study period was from Aug 2018 to December, 2018. A total of 98 consecutive cases were included those who were at and above18 years, have a definite psychiatric disorder and history of suicidal attempt. We conducted direct interviews with those who had given informed consent for interviews. Initially by a brief, semistructured questionnaire (in Bangla) was used to obtain information regarding socio-demographic information and then interview focused on their history of suicidal attempt and behavior. Psychiatric morbidity was assessed using the Diagnostic \& Statistical Manual of Mental Disorders- $5^{\text {th }}$ Edition (DSM-5) by the researcher. Data analysis was performed by Statistical Package for Social Science (SPSS), version-24. The results were analyzed using appropriate statistical measures.

\section{Results}

The study identified the socio-demographic characteristics of the respondents including age, sex, educational level, habitat, religion, family pattern, number of family members, marital status, and monthly income. Most of the patients were in the age group 21-30 years $(53.1 \%)$ followed by the age group of less than 20 years $(21.4 \%)$. Mean age \pm SD was $27.02 \pm 8.42$, more suicidal attempts were found in females $(62.2 \%)$. Suicidal attempts were more (57.1) in the urban population, from the nuclear family $(73.5 \%)$ and $35.7 \%$ of them studied up to SSC. Occupational background revealed that housewives (35.7) are more vulnerable to suicide and less common in service holders (8.2\%). Marital status showed that $51 \%$ were married.
Table 1: The findings of the socio-demographic characteristics are presented $(n=98)$

\begin{tabular}{|c|c|c|}
\hline Socio-demographic variables & Frequency & Percent \\
\hline \multicolumn{3}{|l|}{ Age (Years) } \\
\hline$<20$ & 21 & 21.4 \\
\hline $21-30$ & 73 & 53.1 \\
\hline $31-40$ & 17 & 17.3 \\
\hline $41-50$ & 8 & 8.2 \\
\hline Mean age \pm SD (Min-Max) & $27.02 \pm 8.42(11-50)$ & \\
\hline \multicolumn{3}{|l|}{ Sex } \\
\hline Male & 37 & 37.8 \\
\hline Female & 61 & 62.2 \\
\hline \multicolumn{3}{|l|}{ Religion } \\
\hline Muslim & 93 & 94.9 \\
\hline Hindu & 5 & 5.1 \\
\hline \multicolumn{3}{|l|}{ Habitat } \\
\hline Urban & 56 & 57.1 \\
\hline Rural & 42 & 42.9 \\
\hline \multicolumn{3}{|l|}{ Education level } \\
\hline Illiterate & 4 & 4.1 \\
\hline Primary & 19 & 19.4 \\
\hline SSC & 35 & 35.7 \\
\hline HSC & 20 & 20.4 \\
\hline Graduate & 14 & 14.3 \\
\hline Post-graduate & 6 & 6.1 \\
\hline \multicolumn{3}{|l|}{ Marital status } \\
\hline Married & 50 & 51.0 \\
\hline Unmarried & 40 & 40.8 \\
\hline Divorced & 4 & 4.1 \\
\hline Separated & 4 & 4.1 \\
\hline \multicolumn{3}{|l|}{ Occupation } \\
\hline Unemployed & 24 & 24.5 \\
\hline Employed & 8 & 8.2 \\
\hline Sacked & 2 & 2.0 \\
\hline Student & 25 & 25.5 \\
\hline Housewife & 35 & 35.7 \\
\hline Day laborer & 2 & 2.0 \\
\hline Others & 2 & 2.0 \\
\hline \multicolumn{3}{|l|}{ Family type } \\
\hline Nuclear & 72 & 73.5 \\
\hline Joint & 26 & 26.5 \\
\hline $\begin{array}{l}\text { Mean } \pm \text { SD of Monthly } \\
\text { family income (BDT) }\end{array}$ & $\begin{array}{c}33244.90 \pm 38039 \\
(6000-255000)\end{array}$ & \\
\hline
\end{tabular}

Table 2 presents the pattern, method, precaution and intent, frequency and timing of suicidal attempts. From our current study we found that the mean suicidal attempt \pm SD was $2.63 \pm 2.84$, Communication intent was $20.4 \%$, a suicidal note was put by $10.2 \%$, the final act was done by $1 \%$. The preferred location of the action was at home (90.8\%). More than half (59.2 
$\%$ ) sample choose day time for their suicidal attempt. Method of suicide was by hanging (25.5\%), medicine (22.4\%), cut injury $(17.3 \%)$, the ligature around the throat $(10.2 \%)$, OPC $(9.2 \%)$, fire setting $(4.1 \%)$ and others $(11.2 \%)$. Materials for attempt mainly collected from home (72.4\%), pharmacy (24.5\%). Help nearby was present in $72.4 \%$ and help shouted for $19.4 \%$ person with suicidal attempt. Precaution against rescue was found in a few cases (18.4\%). Among the participants, intent to die was present in $65.3 \%$ and death may occur if no medical management was given in $5.1 \%$ cases. Hospitalization needed for $34.7 \%$ of the attempters. A significant number (34.7\%) of them had a plan to commit suicide again. Family history of suicidal attempt was evident in $17.3 \%$.

Table2: Distribution of the patients according to suicidal attempt and DSH ( $n=98)$

\begin{tabular}{|c|c|c|}
\hline Suicidal attempt/DSH & Frequency & Percent \\
\hline \multicolumn{3}{|l|}{ Number of attempts } \\
\hline Mean \pm SD (Min-Max) & $2.63 \pm 2.84(1-20)$ & \\
\hline Communicated intent & 20 & 20.4 \\
\hline Suicide note & 10 & 10.2 \\
\hline Final acts & 1 & 1.0 \\
\hline \multicolumn{3}{|l|}{ Location } \\
\hline Home & 89 & 90.8 \\
\hline Outside of home & 9 & 9.2 \\
\hline \multicolumn{3}{|l|}{ Timing } \\
\hline Day & 58 & 59.2 \\
\hline Night & 35 & 35.7 \\
\hline Evening & 5 & 5.1 \\
\hline \multicolumn{3}{|l|}{ Method } \\
\hline Hanging & 25 & 25.5 \\
\hline Medicine & 22 & 22.4 \\
\hline Fire set & 4 & 4.1 \\
\hline Ligature around throat & 10 & 10.2 \\
\hline OPC & 9 & 9.2 \\
\hline Cut injury & 17 & 17.3 \\
\hline Others & 11 & 11.2 \\
\hline \multicolumn{3}{|l|}{ Collection of materials } \\
\hline Home & 71 & 72.4 \\
\hline Pharmacy & 24 & 24.5 \\
\hline Not applicable & 3 & 3.1 \\
\hline Help nearby & 71 & 72.4 \\
\hline Precaution against rescue & 18 & 18.4 \\
\hline Intent to die & 64 & 65.3 \\
\hline Death if no medical Mx & 5 & 5.1 \\
\hline Hospitalization & 34 & 34.7 \\
\hline Future plan & 34 & 34.7 \\
\hline
\end{tabular}

\section{Discussion}

\section{Age}

In this study the mean age of the sample being $27.02 \pm 8.42$ (1150 ) years may indicate that, in a psychiatric hospital, suicide is a problem of young adults. A similar finding was found in a general hospital based Indian study, where the mean age was $27.31 \pm 8.68$ years. ${ }^{9}$ Another study found that in young adults (15 to 35 years) actual suicide attempts have become more common, and are key indicators of further suicidal. ${ }^{10}$ In a hospitalbased study in Lucknow city, consisted of a series of 100 cases of attempted suicide who were hospitalized in medical or psychiatric wards, revealed about $80 \%$ subjects were in the age range of 15-34 years and psychiatric disorders were observed in $62 \%$ of these subjects. ${ }^{11}$

\section{Sex}

In our study $62.2 \%$ of subjects were female with suicidal attempts. Near about a similar (55\%) feature was evident in a study in East London. ${ }^{12}$ Different finding was documented in another Indian study, where male was predominant in the suicidal attempt $(59 \%) .{ }^{8}$ The difference in male-female attempter with a diagnosed psychiatric disorder was relatively more than in the general population. The suicide rate for females in all age groups (8.2 per 100,000 populations) is higher than in males (6.5 per 100,000 populations) in Bangladesh. ${ }^{13}$

\section{Habitat}

This study showed that suicidal attempt was relatively more $(57.1 \%)$ among patients with urban origin. This finding is not uncommon in other Asian countries. An Indian study revealed that in psychiatric illness suicide attempters were mostly (96\%) came from urban area. ${ }^{12}$ Iranian researcher Mohammad-R M et al. found in their study that, the majority of attempters were married, more highly educated, female, retired, and lived in urban areas. $^{14}$. Surprisingly all cases of personality disorder with suicidal attempt $(16.1 \%)$ were from urban backgrounds with significant $p$-value $(p=0.009)$.

\section{Education}

Suicidal attempt was found more (35.7\%) in education level up to SSC and HSC (20.4\%) and primary $19.4 \%$. It is not unusual because in Government psychiatric hospital people are coming from medium education level and aware of psychiatric illness too. The similarity was found in another study conducted by Feroz and Colleagues. ${ }^{15}$ They showed that of those who committed suicide, around one third (33.3\%) had education up to secondary level and another $28.6 \%$ up to primary level. Whereas another study in rural India showed the majority $(33.3 \%)$ of the female cases were illiterate $(p=0.018)$ and $45.7 \%$ of the people who committed or attempted suicide belonged to the least educated class. Although $30.4 \%$ of males were educated up to the secondary level. ${ }^{16}$ 


\section{Marital status}

In the study population $50.0 \%$ were married, and single were $40.8 \%$. This finding indicates that marriage is not a protective factor in psychiatric patients from the suicidal attempt. Higher rate was seen in the Sundarban region of India in 2013, where they found more than half of the psychiatric patients $(65.2 \%)$ were married with suicidal attempts. ${ }^{16}$

Occupation

Housewives (35.7\%), students (25.5\%) and unemployed (24.5\%) were three commonest occupational categories involved in a suicidal attempt. In another subcontinental area, the Himachal Pradesh of India had a high frequency of self-harm attempts among housewives (32\%) and students (28\%). ${ }^{17}$

Family type

The current study showed that near about three fourth of $(73.5 \%)$ psychiatric patients with suicidal attempts were from nuclear family and the rest of them were from a joint family. This finding indicates that a joint family can provide better monitoring for these patients.

A meta-analysis on suicide behavior in Bipolar-I and Bipolar-II disorder showed that poor social support is an important indicator for psychiatric patients having suicidal attempts. ${ }^{18}$

Regarding the economic status of our study group we found that the Mean \pm SD (min-Max) was 33244.90 38039 (6000255000) which was not significant. The different findings were seen in India where most of the attempters had a middle socioeconomic status (SES), amongst which the majority (86.8\%) were lower-middle. Significantly more attempters with upper SES reported psychiatric illness $(p<0.05) .{ }^{8}$ A Community Survey on the prevalence of suicidal attempts and deaths in rural Bangladesh revealed the majority (45.7\%) of the people who committed or attempted suicide was of the lower class, $37.1 \%$ were of the lower middle class, $14.3 \%$ were of the middle class and $2.9 \%$ were of the upper class. ${ }^{15}$

\section{Suicide pattern}

To know the pattern of suicidal attempt among the study group, information was collected about the number of attempts, help nearby, suicidal intent, any note about suicide, method used, preferred time, etc. It was found that the mean number of attempts \pm SD was $2.63 \pm 2.84$. It is far more than another hospital-based study in East London where $76 \%$ of cases had a history of single attempt and $23 \%$ had a history of two attempts. ${ }^{12}$ Evaluation of behaviors related to the suicide attempt revealed that almost three fourth $(72.4 \%)$ of the individuals attempting suicide had somebody "present" and "nearby or in contact" at the time of the suicide attempt where the number was found relatively low (45.03\%) in another study. ${ }^{19}$ There were only $20.4 \%$ of patients had to communicate intent. Similar findings were documented in a study in Canada. ${ }^{20}$

In our study only $19.4 \%$ of patients were shouted for help which is near about half of a study finding $(31.3 \%),{ }^{20}$ precautions against rescue were $18.4 \%$, rest $(81.6 \%)$ of them had no precaution against discovery. It is much higher than a study conducted by Granello DH where it was than half $(52.34 \% 0) .{ }^{19}$ Time of attempt suicide revealed that more than half $(59.2 \%)$ patients choose the day time when intervention was easy. It may because most of our psychiatric patients lived with family members or attendant any of their family members remain at home. The scenario of a developed country is different, study findings showed it was much less $(32.20 \%) .{ }^{20}$ This demonstrates the importance of educating the families and friends of at-risk psychiatric patients regarding warning signs and communication strategies. The current study sample also showed that most cases $(65.3 \%)$ of suicide attempts had intent to die and the majority of patients believed that the attempt would lead to death. A large number of participants have had intent to die but a little number (10.2\%) left the suicidal note. A Canadian study showed different scenarios, where more than one-quarter $(26.92 \%)$ of the participants who had attempted suicide left a note. ${ }^{20}$ However, the proportion of individuals attempting suicide with high intent to die in this sample appears greater than other samples, in which half of the participants report that they had low intent to die or attempted as a "cry for help". ${ }^{21}$

The primary method of attempt was by hanging $25.5 \%$, medicine $22.4 \%$ and cut injury were $17.3 \%$ in the current study. But pharmaceutical overdose among the case participants (73.3\%) were showed in a case-control study conducted in Ontario, Canada. ${ }^{20}$ Preference for hanging as a method of choice may be due to sudden decision making or due to impulsivity. Another study in India showed that poisoning, hanging, and drowning have been the common methods for suicide attempts in India. Physical methods were more frequently used by those with unequivocal intent to die, those from extended families, repeaters, substance abusers, and psychiatric patients other than depressives. ${ }^{22}$

Most patients with a psychiatric diagnosis (90.8\%) tried to commit suicide at home, it may be due to most of them remain at home or considered as a safe place for an attempt. These findings were supported by a cross-sectional study where the place of $80 \%$ suicide attempts were at home and $9.3 \%$ in public places. ${ }^{23}$ They collected the materials mostly from home $(72.4 \%)$ which were easily available and then from the pharmacy (24.5\%). From these we can say that majority of patients did not have any long term plan.

The future plan was described by a significant number (34.7\%) of participants. It's a very alarming number and indication for more attention to the patient's current intervention and family education. Forty-three (8\%) participants reported that they were still thinking about suicide (currency), 105 (21\%) reported that they had often thought about killing themselves (frequency), 76 $(15 \%)$ reported that they had thought seriously about killing themselves (seriousness), and 65 (13\%) reported that they had thought about killing themselves for a long time (duration). ${ }^{24}$

Death may occur if no medical management was given in few cases $(5.1 \%)$. It is not unlikely as most of them had no long term plan to die and suicide note left by one-tenth attempters. But study from developed country showed a much higher rate $(53.07 \%) .{ }^{20}$ 
Most of the patients had a nonfatal injury or attempt. Among them $34.7 \%$ of cases required hospitalization to manage the critical condition of patients with psychiatric disorders. A study on schizophrenia and other psychotic disorder were found a higher proportion were admission to the hospital after a suicide attempt (22\%) than those initially admitted without a previous suicide attempt (7\%). ${ }^{25}$

\section{Conclusions}

This study indicates that suicidal behavior is a complex phenomenon. It is also clear that adequate research must be performed in patients with psychiatric disorders to obtain the associated risk factors. This information is much needed to assist the suicide prevention programs and education at various levels of society. Findings regarding the youth and female psychiatric patients are more vulnerable groups and hanging and medicine were frequently used indicates several consequences including more hospitalizations. Means restriction, such as no medicine from the pharmacy without registered physician's prescription, can reduce suicidal attempts. Larger scale studies are needed to establish the temporal association between socio-demographic variables and attempted suicide and identify unique risk factors for them.

\section{References}

1. Bachmann S. Epidemiology of Suicide and the Psychiatric Perspective. Int. J. Environ. Res. Public Health 2018;15:1425.

2. Schlebusch L. Suicidal behavior in South Africa. Pietmarizburg:University of Kwa-Zulu Natal Press; 2005. p.178-94.

3. Harris EC, Barraclough B. Suicide as an outcome for mental disorders: A meta-analysis. Brit J Psychiat 1997; 170:205-28.

4. Cavanagh JT, Carson AJ, Sharpe M, Lawrie SM. Psychological autopsy studies of suicide: a systematic review. Psychol Med 2003;33: 395-405.

5. Brent DA, Mann JJ. Family genetic studies, suicide, and suicidal behavior. Am J Med Genet C Semin Med Genet. 2005;133:13-24.

6. Wasserman D, Wasserman C. editors. Oxford Text Book of Suicidology and Suicide Prevention. Oxford University Press; 2009.

7. Sadock BJ, Sadock VA, Ruiz P. Synopsis of psychiatry: behavioral sciences clinical psychiatry. 11th ed. New York:Wolters Kluwer; 2015. p.764.

8. Kar N. Profile of risk factors associated with suicide attempts: A study from Orissa, India. Indian J Psychiatry 2010;52(1):48-56.

9. Rao KN, Kulkarni RR, Begum S. Comorbidity of psychiatric and personality disorders in first suicide attempter. Indian J Psychol Med 2013 Jan-Mar;35(1): 75-9.

10. Hawton K, Witt KG, Salisbury TL, Arensman E, Gunnell $D$, Hazell $P$, et al. Psychosocial interventions following self-harm in adults: a systematic review and metaanalysis. Lancet Psychiat 2016;3:740-50.
11. Gupta SC, Singh H. Psychiatric illness in suicide attempters; Indian J Psychiatry 1981 Jan-Mar;23(1):6974.

12. Uys H. Agents used and profiles of non-fatal suicidal behavior in Mdantsane, East London: Part 1. J Psychiatry 2014;17:128.

13. Mashreky SR, Rahman F, Rahman A. Suicide kills more than 10,000 people every year in Bangladesh. Arch Suicide Res 2013;17:387-96.

14. Mohammadi MR, Ghanizadeh A, Rahgozart A, Noorbala A A, Malekafzali $H$, Davidian $H$, et al. Suicidal attempt and psychiatric disorders in Iran. Suicide Life Threat Behav 2005;35(3):309-16.

15. Feroz AH, Islam SN, Reza S, Rahman AM, Sen J, Mowla $M$, et al. A community survey on the prevalence of suicidal attempts and deaths in a selected rural area of Bangladesh. JOM 2012;13:3-9.

16. Chowdhury AN, Banerjee S, Brahma A, Hazra A, Weiss MG. Sociocultural context of suicidal behavior in the Sundarban region of India. Psychiatry J [serial online] 2013 [cited 2020 Jan 05]:[8 screens]. Available from:URL: https://www.hindawi.com/journals/psychiatry/2013/ 486081/\#abstract

17. Sharma RC. Attempted suicide in Himachal Pradesh. Indian J. Psychiatry 1998;40:50-4.

18. Novick DM, Swartz HA, Frank E. Suicide attempts in bipolar I and bipolar II disorder: a review and metaanalysis of the evidence. Bipolar Disord 2010;12:1-9.

19. Granello $\mathrm{DH}$. The process of suicide risk assessment: twelve core principles. JCD 2010;88(3):363.

20. Bhatt M, Perera S, Zielinski L, Eisen RB, Yeung S, ElSheikh W, et al. Profile of suicide attempts and risk factors among psychiatric patients: a case-control study. PLoS ONE 2018;13(2).

21. Kessler RC, Borges G, Walters EE. Prevalence of and risk factors for lifetime suicide attempts in the National Comorbidity Survey. Arch. Gen. Psychiatry 1999;56(7):617-26.

22. Arun M, Yoganarasimha K, Palimer V, Kar N, Mohanty MK. Parasuicide - an approach to the profile of victims. J Indian Acad Forensic Med 2004;26:58-61.

23. Choo CC, Harris KM, Chew PKH, Ho RC .Clinical assessment of suicide risk and suicide attempters' selfreported suicide intent: A cross sectional study. PLoS ONE.2019; 14(7): e0217613. https://doi.org/10.1371/ journal.

24. Miranda R, Ortin A, Scott M and Shaffer D. Characteristics of suicidal ideation that predict the transition to future suicide attempts in adolescent. J Child Psychol Psychiatry. 2014 Nov; 55(11): 1288-1296.

25. Radomsky D E, Haas G L, Mann JJ, and Sweeney JA. Suicidal Behavior in Patients With Schizophrenia and Other Psychotic Disorders. Am J Psychiatry 1999; 156:1590-1595. 